\title{
What Role Do Social Norms Play in the Context of Men's Cancer Screening Intention and Behavior? Application of an Extended Theory of Planned Behavior
}

\author{
Monika Sieverding \\ University of Heidelberg
}

\author{
Uwe Matterne \\ University Hospital Heidelberg
}

\author{
Liborio Ciccarello \\ University of Mannheim
}

\begin{abstract}
Objective: Our research investigated the role of social norms in an extended theory of planned behavior (TPB) in the explanation of prostate/colorectal cancer screening (CS) intention and the prediction of CS uptake among men. Design: A cross-sectional study (Study 1) assessed sociodemographic and TPB variables (extended by descriptive norm) in 2,426 German men (mean age 56.3 years) who differed in their past CS behavior. A subsample of Study 1 (former nonattenders and irregular attenders, $n=$ 1,032) were followed up 12 months later (Study 2). Main Outcome Measures: The authors measured cross-sectionally the intention to undergo a CS examination within the next 12 months (Study 1), and longitudinally self-reported uptake of prostate and/or colorectal CS within the last 12 months (Study 2). Results: When sociodemographic variables were controlled, TPB variables predicted a substantial amount of CS-intention $\left(\Delta R^{2}=.49\right)$. Descriptive norm explained variance beyond the classic TPB variables and interacted significantly with subjective norm. Significant predictors of CS uptake were intention and subjective norm with the latter having a different effect in the two subgroups: a high subjective norm (assessed at T1) was associated with higher CS attendance in (former) nonattenders but lower CS attendance in irregular attenders in the following 12 months. Conclusion: Social norms play an important role in men's CS intention and behavior. For intention formation, descriptive norm is influential in addition to subjective norm. The fact that a high subjective norm resulted in a lower likelihood of screening among irregular attenders suggests possible reactance effects.
\end{abstract}

Keywords: cancer screening, men, theory of planned behavior, social norms, descriptive norm

Cancer is a major threat to people's health throughout the world, claiming many lives, and is associated with severe suffering and pain. The most often diagnosed cancers in German men are prostate cancer (PC), with 58,570 newly diagnosed cases per year, and colorectal cancer (CRC), with 37,250 cases (Robert Koch-Institut \& Gesellschaft der epidemiologischen Krebsregister, 2008). Screening examinations that are able to detect a tumor at an early stage exist both for PC and CRC. When detected early, treatment is more effective in improving cancer survival than at advanced stages of the disease. In Germany, the standard CS examination for

Monika Sieverding, Department of Psychology, University of Heidelberg, Heidelberg, Germany; Uwe Matterne, Clinical Social Medicine, University Hospital Heidelberg, Heidelberg, Germany; Liborio Ciccarello, Department of Social Psychology, University of Mannheim, Mannheim, Germany.

Monika Sieverding was supported by a grant from the Minstery of Baden-Württemberg. This research was funded by a grant from the "Deutsche Krebshilfe" (German Cancer Aid).

Correspondence concerning this article should be addressed to Monika Sieverding, Department of Psychology, University of Heidelberg, Hauptstr. 47-51, 69117 Heidelberg, Germany. E-mail: monika.sieverding@ psychologie .uni-heidelberg.de men is offered annually from age 45 and includes a digital-rectal examination (DRE) of the prostate. A prostate-specific antigen (PSA) test is carried out if abnormalities are detected. From age 50, CRC screening is offered. An fecal occult blood test (FOBT) is recommended, which is usually handed out during the standard CS examination. Since 2002, individuals from age 55 can opt for a colonoscopy every 10 years in lieu of an FOBT every 2 years.

As in the United States, the CS program in Germany is opportunistic in nature. Although there are no costs for participation (paid for by health insurance), acceptance of the program is unsatisfactory. A survey among a representative sample of German men aged 45 to $70(N=10,659)$ revealed that $32 \%$ had never attended any prostate CS (Sieverding, Matterne, Ciccarello, \& Luboldt, 2008). A community survey in the United States $(N=$ 2,500 ) showed that $48 \%$ of the men reported no prior PC screening by PSA or DRE (Nagler et al., 2005). Regarding CRC screening, studies from several European countries demonstrated that men make less use of CRC screening tests than women, particularly with respect to FOBT use (for France: Faivre et al., 2004; for the U.K.: Hardcastle et al., 1996; for Finland: Malila, Oivanen, \& Hakama, 2008). In a recent German survey, $30 \%$ of the men but only $17 \%$ of the women aged 50 to 70 years reported no prior use of an FOBT $(N=15,810)$ (Sieverding, Matterne, \& Ciccarello, 
2008). In sum, CS measures appear underutilized by men in many countries.

\section{Which Factors Are Associated With Men's Cancer Screening?}

In order to explain men's CS participation, a number of studies-mainly from the United States-investigated sociodemographic correlates and predictors of PC and CRC screening participation. Positive associations of participation in PC or CRC screening were found with age (Swan, Breen, Coates, Rimer, \& Lee, 2003), education (Cokkinides, Chao, Smith, Vernon, \& Thun, 2003; Seeff et al., 2004), income (Breen, Wagener, Brown, Davis, $\&$ Ballard-Barbash, 2001), health insurance coverage (Cokkinides et al., 2003), and marital status (Nijs, Essink-Bot, DeKoning, Kirkels, \& Schroder, 2000), although not all studies produced unequivocal findings. In our research we were interested in $p s y$ chological variables in the context of men's CS behavior, applying an extended theory of planned behavior (TPB) (Ajzen, 1991). We chose the TPB mainly for two reasons: The theory has demonstrated good predictive power in several domains of health-related behavior, and it includes normative social influences, which we assumed to be particularly relevant to men's CS behavior.

\section{The Theory of Planned Behavior and Its Extension by Descriptive Norm}

The TPB provides a conceptual account of the way in which attitude, subjective norm, and perceived behavioral control (PBC) predict behavioral intention, which in turn is seen as the most proximal determinant of actual behavior. The theory has received substantial empirical support across many health behaviors (Conner \& Sparks, 2005; Godin \& Kok, 1996). A meta-analysis by Armitage and Conner (2001) found subjective norm to be the weakest predictor of intention in comparison to attitude and PBC. This finding was attributed to a combination of poor measurement and the need for an expansion of the normative component. Other authors also believe the normative component to be too narrowly conceptualized in the model (Kallgren, Reno, \& Cialdini, 2000). Deutsch and Gerard (1955) already distinguished two types of social influences that guide behavior: normative social influence as "the influence to conform with the positive expectations of another," and informational social influence, which they defined as "the influence to accept information obtained from another as evidence about reality" (Deutsch \& Gerard, 1955, p. 629). To put it more simply: Social norms may refer to (a) what is commonly approved, or (b) what is commonly done. Cialdini and colleagues (Cialdini, Reno, \& Kallgren, 1990) called the first type of norm, which is very similar to the construct "subjective norm" in the TPB-model, "injunctive norm." The second type of norm, pertaining to what is typically done in a given setting (Reno, Cialdini, \& Kallgren, 1993), was labeled "descriptive norm." Over the last few years, several studies have assessed the role of descriptive norm in the context of health-relevant behavior, for example, exercise behavior, healthy eating, illicit drug use, or condom use. A metaanalysis (Rivis \& Sheeran, 2003) of 16 studies examining the relationship between descriptive norm and intention in the context of health-related behavior, found that descriptive norm increased the variance explained in intention after attitude, subjective norm, and perceived behavioral control had been taken into account, contributing an additional 5\% over and above the TPB predictors.

\section{TPB and Men's Cancer Screening Attendance}

Most studies examining the TPB in the context of CS intention and/or behavior have focused exclusively on women's CS (see, e.g., the recent meta-analysis of TPB/TRA studies predicting screening attendance by Cooke $\&$ French, 2008). The few studies we found that applied the TPB to men's attendance at CS examinations were cross-sectional in nature and concentrated on the intention to undergo a CS examination. One study (Berglund, Nilsson, \& Nordin, 2005) identified attitude as the main predictor of the intention to take a PSA test for Swedish men. Another study assessed the intention to undergo a stomach CS in a Korean sample; in this study, attitude and PBC emerged as significant predictors of intention (Hahm, Choi, Kye, Kwak, \& Park, 2007). However, actual uptake of a CS examination was not followed up in either study. To our knowledge, there is only one longitudinal study examining the role of TPB variables in predicting the participation in CRC screenings for high- versus low-risk siblings of either sex (DeVellis, Blalock, \& Sandler, 1990). The authors found that TPB variables were better at predicting intention and behavior for the average-risk group rather than for the high-risk group. Generalizing these results is difficult as only a few men with average risk participated in this study $(n=52)$, sociodemographic variables were not controlled for, and, most importantly, participants were invited to take part in CS and sent test kits to be returned by mail. Invitation letters tend to increase attendance rates in comparison to opportunistic screening systems (Classen \& Lambert, 2008). We found no study applying the TPB to CS intention and behavior in a large sample of men with average risk, controlling for sociodemographic variables, and assessing the actual CS behavior over a longer period of time in an opportunistic screening setting. The role of descriptive norm in men's CS intention and/or behavior has not been studied to date.

\section{What Motivates Men To Undergo a Cancer Screening Examination?}

While women often receive a recommendation for a CS examination during their routine visits to a gynecologist (Klug, Hetzer, \& Blettner, 2005), men are not as regularly in touch with the medical system. They make less use of the medical system, especially for preventive reasons, and have fewer physician visits, as compared to women (Evans, Brotherstone, Miles, \& Wardle, 2005). In a representative survey in 29,000 German households, nearly half of the men (46\%) but only a third of the women $(34 \%)$ aged 50 to 70 years stated that they had never received a physician's recommendation to undergo a CS (Sieverding, Matterne, \& Ciccarello, 2008). It was our assumption that especially in countries with an opportunistic CS system, men's behavior is guided by what their significant others expect them to do (subjective norm), but also what other comparable men do (descriptive norm). The first goal of our research was to compare men, differing significantly in past CS behavior, in psychological and sociodemographic variables, and to identify the relevant variables that can explain the intention to undergo a CS examination (Study 1). The second goal 
was to identify predictors of the uptake of CS examinations in a longitudinal study in a subsample of Study 1 (Study 2).

\section{Study 1}

The purpose of Study 1 was to compare three groups of men who differed in their past CS behavior and to investigate the role of TPB variables extended by descriptive norm to predict CS intention, while controlling for sociodemographic variables. We expected social influences, as operationalized by subjective and descriptive norm, to be important predictors of CS intention.

\section{Method}

\section{Participants and Procedure}

The participants for Study 1 were recruited out of a larger representative German sample of 11,178 men and 12,261 women aged 45 to 70 years who had participated in a survey on prevalence and sociodemographic correlates of CS in 2004 (Sieverding, Matterne, \& Ciccarello, 2008; Sieverding, Matterne, Ciccarello et al., 2008). One selection criterion was the ability to clearly assign the men to one of three distinct groups as a function of their past CS behavior: nonattenders (NAs), irregular attenders (IAs), and regular attenders (RAs). Nonattenders were those who in the 2004 survey had reported that they had (a) never undergone any prostate CS (neither DRE nor PSA-Test) and (b) never undergone any colorectal CS (neither FOBT nor colonoscopy). Irregular attenders stated in 2004 that they had undergone in the past (a) prostate CS (DRE) irregularly and (b) colorectal CS (FOBT) irregularly. Regular attendance was assigned to those who in the 2004 survey indicated that they had undergone (a) prostate CS (DRE) annually and (b) colorectal CS (FOBT) regularly every 1 or 2 years. Men with a personal history of cancer were excluded. As we planned to conduct a follow-up with IAs and NAs (see Study 2), we recruited a comparatively larger group of NAs because we believed the likelihood for previous NAs to become first-time attenders within 12 months to be relatively small. Our aim was to get at least 1,000 NAs, 500 IAs, and 500 RAs for Study 1.

Altogether, 3,504 men were invited to participate (NAs = 2,000; IAs $=752$; RAs $=752$ ), who received the questionnaires in the mail. These numbers were chosen on the basis of experiences regarding response rates in former surveys on other issues (about $60 \%$ response rates for former surveys) conducted by the research institute (TNS Healthcare, Munich) we cooperated with. Actual participation was higher than expected. A total of 2,801 $($ NAs $=1512$; IAs $=619$; RAs $=670)$ men returned the questionnaire, giving an overall response rate of $79.9 \%$. The difference in response rates across the three groups was significant, $\chi^{2}(2, N=$ $3,504)=65.44, p<.001$; response rates were lowest for the group of NAs and highest for the group of RAs (NAs $=75.6 \%$; IAs $=$ 82.3; RAs $=89.1$. Drop-out analyses detected a small age difference between nonrespondents $(n=703 ; M=53.2, S D=4.9)$ and respondents $(n=2,801 ; M=54.1, S D=5.2), t(3,502)=$ $-4.3, p<.001$. Respondents came from smaller households $(M=$ $2.8, S D=1.2)$ than nonrespondents $(M=3.0, S D=1.3), t(3$, $502)=4.7, p<.001$, and had a slightly higher education $(M=$ $2.8, S D=0.8)$ than nonrespondents $(M=2.7, S D=0.8), t(3$, $395)=-2.7, p<.01$. No other significant differences were found with regard to income, health insurance, or marital status. Men who had given answers about their CS behavior that were not consistent with their answers in 2004 and men who reported a (new) personal cancer diagnosis were excluded from the study, leading to a sample of $N=2,426$ (NAs $=1,284$, IAs $=540$, RAs $=602$ ).

\section{Measures}

CS participation since 2004. This assessed whether respondents had undergone a standard CS examination since participation in the survey in 2004. They were briefly informed about the standard CS examination in Germany, which for men includes a DRE of the prostate and the offer of an FOBT. They were reminded that they had already participated in a survey on their CS behavior and were asked: "Since that survey in Fall, 2004, have you attended such a standard CS examination?" Five responses were possible: "No, and I do not intend to," "No, but I am thinking about it," "No, but I fully intend to," "Yes, for the first time," and "Yes, repeatedly."

Sociodemographic variables. The following sociodemographic variables were assessed: Age in years, (marital) partner status $(0=$ no, $1=$ yes), household size (number of members living in the household), education ( $1=$ no school-leaving certificate, $2=9$ th grade, $3=10$ th grade, $4=$ high school certificate), monthly family income (from $1=$ less than $326 €$ per month to $18=$ more than 5,000 € per month), and health insurance status (with three alternatives: no health insurance, public, or private health insurance).

Psychological variables. TPB constructs were developed according to Ajzen's (Ajzen, 2002a) and Francis et al.'s (2004) recommendations in a battery of elicitation studies, which included, among others, a focus group study (Sieverding \& Dauven, 2005); subsequent pretests led to the selection of the most psychometrically sound items. Attitude toward CS was assessed by responses to the stem "To attend a CS examination would be ..." on five 7-point semantic differentials with the extreme anchors: reassuring - anxiety provoking, useful-useless, pleasant—unpleasant, worthwhile-worthless, not embarrassing-embarrassing. The items showed satisfactory internal consistency (Cronbach's alpha $=.82)$. Subjective norm (Cronbach's alpha $=.86$ ) consisted of three items: "My 'partner,' 'family,' 'most people I consider important,' respectively, think(s), I should undergo a CS," providing answers on a 7-point Likert-scale with endpoints indicating complete disagreement versus complete agreement. Descriptive norm was measured by two items: "What do you think is the percentage of 'men your age' as well as 'men among your circle of friends and acquaintances' who regularly attend CS examinations?" Internal consistency (Cronbach's alpha) was .74. Perceived behavioral control was measured by two items: "To attend a CS examination would be ..." on 7-point Likert-scales with the endpoints "easy" versus "difficult," and "I would find it easy to attend a CS examination" on a 7-point Likert scale with the endpoints "completely disagree" versus "completely agree." Internal consistency (Cronbach's alpha) was .76. Intention to undergo a CS test was measured with two items: "Do you intend to participate in a CS examination within the next 12 months" on a scale from one ("no, under no circumstances") to seven ("yes, at any rate") and "How likely is it (in percent from $0 \%$ to $100 \%$ ) that you will attend 
a CS examination within the next 12 months?" In order to get a composite score for intention we first subtracted one from the first intention measure, then multiplied the second one by six and divided this product by 100 , added the two together and divided that sum by two. The composite intention score with possible values from 1 to 7 showed high internal consistency with the measures on which it was based (Cronbach's alpha $=.98$ ). All other items pertaining to one of the TPB constructs were also combined and divided by the respective number of items to provide an overall score for each construct. If men reported no intention to undergo a CS screening within the next 12 months the reasons were asked for ("If not, why not?"). Two alternative answers (identified in preliminary studies) were offered as possible reasons for no (actual) screening intention: "I've just had a CS examination recently" and "My doctor has recommended that I undergo a CS at longer intervals," and as a third alternative, the men could affirm the item "Other reason(s)" with an option to name these reason(s).

\section{Statistical Methods}

We first used descriptive statistics to describe the variables for all participants $(N=2,426)$, as well as separating them into the three subgroups. ANOVAs were conducted to test whether group membership was significantly associated with the variables. Post hoc analyses were conducted by Bonferroni tests. Univariate correlational analyses on all variables were conducted. Predictors of intention were analyzed by a hierarchical multiple regression model. We excluded 119 men with no intention to undergo a CS examination within the next 12 months from the correlational and regression analysis reported here, because they had recently had a CS examination $(N=$ $2,307)$. Sociodemographic variables that were significantly correlated with intention were entered into the hierarchical model in the first step, followed by the classical TPB variables, descriptive norm, interactions between TPB variables, and past
CS behavior in subsequent steps. Interaction terms were constituted by multiplying mean-centered variables to guard against multicollinearity. We entered past CS behavior (coded as $0=$ "never," 1 = "irregular," and 2 = "regular") in the last step after all other variables had been entered, as suggested by Ajzen (2002b) and Norman and Conner (1996).

\section{Results}

\section{Descriptive Statistics}

Sociodemographic variables. The mean age was 56.3 years $(S D=5.1)$. The majority $(91 \%)$ was married or living with a partner, the mean household size was 2.8 members $(S D=1.2)$, and the mean family income was about $2.500 €$ per month. Nearly all men (99\%) reported having a school-leaving certificate, with $45 \%$ having a 9 th grade, $32 \%$ a 10 th grade, and $23 \%$ a high school certificate. All of the men held health insurance, the majority $(85 \%)$ was insured by public health insurance, $15 \%$ by private health insurance. The sociodemographic variables for the sample stratified by past CS participation status are displayed in Table 1. An ANOVA detected a significant effect of age $\left(p<.001, \eta^{2}=\right.$ .100) such that RAs were older than IAs and NAs. RAs had a higher income than NAs and lived in smaller households. The respective effect sizes were very small, however $\left(\eta^{2}=.007\right.$ and .012). The three groups of men did not differ on any other sociodemographic variables.

Psychological variables. The NA, IA, and RA groups differed significantly on each of the psychological variables (see Table 1). Effect sizes of differences on psychological variables were high in comparison to effect sizes for sociodemographic variables ( $\eta^{2}$ between 0.142 and 0.376 ). NAs reported a more negative attitude and a lower perceived behavioral control toward CS compared to IAs and RAs. They reported a lower subjective norm and estimated on average that only $27.5 \%$ of

Table 1

Demographic and Psychological Variables as a Function of Prior Attendance Patterns (Study 1)

\begin{tabular}{|c|c|c|c|c|c|c|c|c|c|c|c|c|}
\hline \multirow[b]{2}{*}{ Variable } & \multicolumn{3}{|c|}{$\begin{array}{l}\text { Non-attenders } \\
(n=1284)\end{array}$} & \multicolumn{3}{|c|}{$\begin{array}{l}\text { Irregular attenders } \\
\qquad(n=540)\end{array}$} & \multicolumn{3}{|c|}{$\begin{array}{l}\text { Regular attenders } \\
\quad(n=602)\end{array}$} & \multicolumn{3}{|c|}{ Difference } \\
\hline & $M$ & $S D$ & $\%$ & $M$ & $S D$ & $\%$ & $M$ & $S D$ & $\%$ & $F$ & $\chi^{2}$ & $\eta^{2}$ \\
\hline \multicolumn{13}{|l|}{ Sociodemographic } \\
\hline Age (years) & $54.9_{\mathrm{e}}$ & $(4.8)$ & & $57.0_{\mathrm{e}}$ & $(5.1)$ & & $58.7_{\mathrm{e}}$ & (4.9) & & $135.4^{* * * *}$ & & 0.100 \\
\hline Household size (members) & $2.9_{\mathrm{e}}$ & (1.3) & & 2.7 & $(1.2)$ & & $2.6_{\mathrm{e}}$ & $(1.1)$ & & $9.2^{* * * *}$ & & 0.007 \\
\hline Family income $^{\mathrm{a}}$ & $9.8_{\mathrm{e}}$ & $(4.2)$ & & 10.8 & $(4.1)$ & & $10.6_{\mathrm{e}}^{\mathrm{c}}$ & (3.9) & & $14.3^{* * * *}$ & & 0.012 \\
\hline Education $^{\mathrm{b}}$ & 2.8 & $(0.8)$ & & 2.8 & $(0.8)$ & & 2.8 & $(0.8)$ & & 0.4 & & \\
\hline With (marital) partner & & & 90.6 & & & 90.4 & & & 93.3 & & 4.3 & \\
\hline With public health insurance & & & 86.2 & & & 85.1 & & & 82.7 & & 3.8 & \\
\hline \multicolumn{13}{|l|}{ Psychological variables } \\
\hline Attitude ${ }^{c}$ & $4.2_{\mathrm{e}}$ & $(1.3)$ & & $5.0_{\mathrm{e}}$ & $(1.2)$ & & $5.8_{\mathrm{e}}$ & $(0.9)$ & & $388.0^{* * * *}$ & & 0.258 \\
\hline $\mathrm{PBC}^{\mathrm{c}}$ & $3.7_{\mathrm{e}}$ & (1.5) & & $5.0_{\mathrm{e}}$ & $(1.5)$ & & $6.1_{\mathrm{e}}$ & $(1.1)$ & & $538.6^{* * * *}$ & & 0.324 \\
\hline Subjective norm ${ }^{\mathrm{c}}$ & $4.2 \mathrm{e}$ & (1.9) & & $4.9 \mathrm{e}$ & $(1.8)$ & & $5.9_{\mathrm{e}}$ & (1.3) & & $191.6^{* * *}$ & & 0.142 \\
\hline Descriptive norm $^{\mathrm{d}}$ & $27.5_{\mathrm{e}}$ & $(16.4)$ & & $36.0_{\mathrm{e}}$ & $(17.4)$ & & $45.0_{\mathrm{e}}^{\mathrm{e}}$ & $(18.2)$ & & $216.1^{* * * *}$ & & 0.154 \\
\hline Intention $^{c}$ & $3.4_{\mathrm{e}}$ & $(1.9)$ & & $5.1_{\mathrm{e}}$ & $(1.9)$ & & $6.6_{\mathrm{e}}$ & $(1.0)$ & & $727.1^{* * * *}$ & & 0.376 \\
\hline
\end{tabular}

Note. Post-hoc multiple comparisons by Bonferroni-tests: means in a row sharing the same subscript differ significantly at $p<.05$.

${ }^{\mathrm{a}}$ Possible values from 1 to $18 .{ }^{\mathrm{b}}$ Scores from 1 to $4 .{ }^{\mathrm{c}}$ Scores from 1 to $7 .{ }^{\mathrm{d}}$ In percent.

${ }^{*} p<.05 . \quad{ }^{* * *} p<.01 . \quad{ }^{* * * *} p<.001$. 
other men of their age would undergo CS on a regular basis (descriptive norm). In comparison, the RAs estimated on average that nearly every second man of their age (45\%) would undergo CS examinations regularly. NAs had a much lower intention to undergo a CS examination within the next 12 months compared to RAs $(M=3.4$ vs. $M=6.6)$. The values on all variables for IAs were between the NAs and RAs.

Relations among variables. Correlations between intention and the other TPB variables were higher than the correlations between reported (past) CS participation and TPB variables (see Table 2). Correlations of both variables with sociodemographic variables were generally small apart from the correlation between intention and age. Education and type of health insurance were not significantly correlated with intention; thus, these variables were excluded from the following regression analyses explaining intention.

\section{Explaining Cancer Screening Intention}

Sociodemographic variables accounted for only $6 \%$ of the variance in intention, most of which could be attributed to age. Adding the classical TPB variables in the second step led to a sharp increase (49\%) in explained variance. Descriptive norm, entered in the third step, increased the variance explained in intention, contributing a further $3 \%$ over and above the TPB predictors. Inclusion of interactions led to a small (1\%) albeit significant increase in explained variance. Past CS behavior, which was introduced in the last step, still added significantly $(6 \%)$ to the prediction of intention (see Table 3). Betas from the final step indicate little influence of sociodemographic variables on intention. TPB variables, particularly attitude, had substantial main effects on intention. Four interaction terms (subjective $\times$ descriptive norm; subjective norm $\times$ attitude; descriptive norm $\times$ attitude; attitude $\times$ PBC) were significant. The interaction between subjective and descriptive norm indicates that when subjective norm was low, descriptive norm became comparatively more important in the prediction of intention than when subjective norm was high. The interactions between $\mathrm{DN}$ and attitude, and attitude and $\mathrm{PBC}$ are to be interpreted in the same fashion. The interaction between $\mathrm{SN}$ and
PBC, on the other hand, suggests that the relationship between $\mathrm{SN}$ and intention became stronger as attitude became more favorable toward CS attendance.

The significant increase in explained variance after entering past CS experience suggests that variables other than those assessed in this study may have to be considered.

\section{Study 2}

The main goal of Study 2 was to assess the behavior of former NAs and IAs after 12 months and to analyze whether sociodemographic and psychological variables assessed at T1, mainly the intention to undergo a CS examination within the next 12 months, are able to predict actual uptake of a CS examination. We only followed up (former) NAs and IAs (but not RAs) because we were interested in the variables determining first time CS attendance (NAs) and repeated attendance (IAs). In (psychological) interventions that aim to improve men's CS participation rates, it is particularly important to target the needs of these men. We also wished to address the question of whether predictors of CS uptake would differ in the two subgroups of men. Regarding another screening behavior (prenatal screening), it has been suggested that the behavior not be considered as a dichotomous variable (to screen or not to screen), but rather as a group of behaviors each with their own set of predictor variables (Marteau, Johnston, Kidd, \& Michie, 1992). A study investigating TPB variables as possible predictors of attendance in general health checks tested this assumption and found evidence in support of it. TPB variables were able to predict behavior for prior nonattenders but not for attenders (Norman \& Conner, 1996). Thus, there may also be differences in predictors of CS attendance as a function of whether a man has or has no previous CS experience.

\section{Method}

\section{Participants and Procedure}

The follow-up (T2) was carried out in February, 2007. Recruitment of the sample was based on the sample from Study 1 (T1).

Table 2

Correlations Between Sociodemographic Variables, TPB Variables, Descriptive Norm, CS-Intention, and Past CS Attendance (Study 1)

\begin{tabular}{|c|c|c|c|c|c|c|c|c|c|c|c|}
\hline Variable & 2 & 3 & 4 & 5 & 6 & 7 & 8 & 9 & 10 & 11 & 12 \\
\hline 1. Age & -.03 & $-.35^{* * * *}$ & $-.10^{* * * *}$ & $-.06^{* *}$ & -.01 & $.15^{* * * *}$ & $.15^{\text {***** }}$ & $.18^{* * * *}$ & $.19^{* * *}$ & $.19^{* * * *}$ & $.32^{* * * *}$ \\
\hline 2. Partner status & & $.40^{* * * *}$ & $.27^{* * * *}$ & -.02 & .00 & .03 & $.30^{* * * *}$ & $.06^{* *}$ & $.05^{*}$ & $.06^{* *}$ & .03 \\
\hline 3. Household size & & & $.32^{\text {**** }}$ & -.02 & -.04 & $-.05^{*}$ & $.09^{\text {******** }}$ & $-.05^{*}$ & $-.05^{*}$ & $-.05^{*}$ & 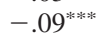 \\
\hline 4. Family income & & & & $.28^{* * * *}$ & $.27^{* * * *}$ & $.06^{* *}$ & $.16^{* * * *}$ & $.05^{*}$ & $.06^{* *}$ & $.12^{* * * *}$ & $.09^{* * * *}$ \\
\hline 5. Education & & & & & $.24^{* * * * *}$ & $.05^{*}$ & $-.06^{* * *}$ & .00 & $.06^{* * *}$ & .03 & .01 \\
\hline 6. Health insurance & & & & & & .03 & .00 & .01 & .04 & .02 & .03 \\
\hline 7. Attitude & & & & & & & $.34^{* * * *}$ & $.34^{* * *}$ & $.73^{* * * *}$ & $.66^{* * *}$ & $.51^{* * * *}$ \\
\hline 8. Subjective norm & & & & & & & & $.37^{* * *}$ & $.30^{* * *}$ & $.47^{* * * *}$ & $.38^{* * * *}$ \\
\hline 9. Descriptive norm & & & & & & & & & $.33^{* * *}$ & $.48^{* * *}$ & $.40^{* * * *}$ \\
\hline 10. $\mathrm{PBC}$ & & & & & & & & & & $.62^{* * * *}$ & $.57^{* * * *}$ \\
\hline 11. Intention & & & & & & & & & & & $.66^{* * * *}$ \\
\hline 12. Past CS attendance ${ }^{a}$ & & & & & & & & & & & \\
\hline
\end{tabular}

Note. $\quad N=2,307$. $\mathrm{CS}=$ cancer screening.

${ }^{\text {a }} 0=$ not attended, $1=$ irregularly attended, $2=$ regularly attended.

${ }^{*} p<.05$. ${ }^{* *} p<.01 .{ }^{* * * *} p<.001$. 
Table 3

Hierarchical Multiple Linear Regression Analysis: Predictors of Cancer Screening Intention Within the Next 12 Months (Study 1)

\begin{tabular}{|c|c|c|c|c|c|}
\hline Step predictor & $\beta_{\text {step 1 }}$ & $\beta_{\text {step 2 }}$ & $\beta_{\text {step } 3}$ & $\beta_{\text {step } 4}$ & $\beta_{\text {step } 5}$ \\
\hline \multicolumn{6}{|l|}{ 1. Sociodemographics } \\
\hline Age & $.19^{* * * *}$ & $.04^{*}$ & .02 & .02 & $-.04^{*}$ \\
\hline Partner status ${ }^{\mathrm{a}}$ & .04 & $-.05^{* *}$ & $-.05^{\text {*** }}$ & $-.04^{*}$ & -.03 \\
\hline Household size & -.05 & -.03 & -.03 & -.03 & -.03 \\
\hline Family income & $.14^{* * * *}$ & $.07^{* * * * *}$ & $.06^{\text {**** }}$ & $.06^{* * * *}$ & $.04^{* *}$ \\
\hline \multicolumn{6}{|l|}{ 2. TPB Variables } \\
\hline Attitude & & $.37^{* * * * *}$ & $.34^{* * * * *}$ & $.31^{* * * * *}$ & $.27^{* * * *}$ \\
\hline Subjective norm (SN) & & $.28^{* * * *}$ & $.22^{* * * * *}$ & $.21^{* * * * *}$ & $.16^{\text {***** }}$ \\
\hline PBC & & $.25^{* * * *}$ & $.23^{* * * *}$ & $.24^{* * * *}$ & $.12^{* * * *}$ \\
\hline 3. Descriptive Norm (DN) & & & $.20^{* * * * *}$ & $.21^{* * * * *}$ & $.17^{* * * *}$ \\
\hline \multicolumn{6}{|l|}{ 4. Interactions } \\
\hline $\mathrm{SN} \times$ Attitudes & & & & .00 & -.01 \\
\hline $\mathrm{SN} \times \mathrm{DN}$ & & & & -.10 (1*** & $-.09^{* * * *}$ \\
\hline $\mathrm{SN} \times \mathrm{PBC}$ & & & & $.08^{*}$ & $.05^{*}$ \\
\hline DN $\times$ Attitudes & & & & $-.06 *$ & $-.05^{*}$ \\
\hline $\mathrm{DN} \times \mathrm{PBC}$ & & & & .01 & .00 \\
\hline Attitudes $\times$ PBC & & & & -.02 & -.06 米 \\
\hline \multicolumn{6}{|l|}{ 5. Past behavior } \\
\hline Past cancer screening attendance ${ }^{\mathrm{b}}$ & & & & & $.33^{* * * *}$ \\
\hline$\Delta R^{2}$ & .06 **** & $.49^{* * * *}$ & $.03^{* * * *}$ & .01 **** & $.06 * * *$ \\
\hline $\operatorname{adj} R_{\text {cum }}^{2}$ & $.06 * * *$ & $.55^{* * * *}$ & $.58^{* * * * *}$ & $.59^{* * * *}$ & $.65^{* * * *}$ \\
\hline
\end{tabular}

Note. $\quad N=2,307$. Significant predictors are shown in bold.

${ }^{\mathrm{a}}$ Coding: $0=$ no partner, $1=$ with partner. ${ }^{\mathrm{b}} 0=$ not attended, $1=$ irregularly attended, $2=$ regularly attended.

${ }^{*} p<.05 .{ }^{* * *} p<.01 .{ }^{* * *} p<.001$.

We selected those men who had consistently reported being either IAs or NAs in the survey in 2004 and in Study 1 in 2006, and who stated in 2006 that they were either thinking about attending or had decided to attend. (We did not follow up on the men who stated that they had decided not to attend a CS in the future). This selection was based on the rationale that we wanted to predict first time attendance of a CS (in hitherto and so far resilient NAs) and repeat attendance in IAs. Nine hundred ten NAs and 308 IAs were selected (total $N=1,218$ ) and sent questionnaires by mail. Of these, 771 NAs (response rate: $84.7 \%$ ) and 261 IAs (response rate: $84.7 \%$ ) returned the follow-up questionnaire (total $N=1,032$ ). Drop-out analyses detected no anomalies between respondents and nonrespondents in terms of age, household size, income, education, health insurance, and marital status.

\section{Measures}

Uptake of cancer screening within the previous 12 months. A single binary outcome variable for uptake of cancer screening was used, because the prostate and colorectal cancer screening examinations for men are frequently combined in Germany. The "standard" CS examination for men (starting at age 45) includes an examination of the genitals and the DRE of the prostate. The recommendation for colorectal CS is usually given during or immediately after this standard CS examination, and the men are handed out a test kit for hidden blood in stool (FOBT). This is why uptake of prostate (DRE) and colorectal CS (FOBT) is highly correlated in German men $(r=.70)$ (Sieverding, Matterne, \& Ciccarello, 2008; Sieverding, Matterne, Ciccarello et al., 2008). Hence, we did not try to determine the predictors of prostate and colorectal cancer screening separately.
Respondents were asked: "Since the last survey at the beginning of 2006 (i.e., within the last 12 months), have you undergone a CS examination (prostate or colorectal CS)?" Four answers could be given: "No, and I do not intend to," "No, but I am thinking about it," "No, but I fully intend to," and "Yes." The answers were then combined to provide a dichotomous measure (No vs. Yes). Those men who had affirmed the question were further asked in detail what specific kind of prostate and/or CS examination they had undergone (four options were assessed: DRE, PSA-Test, colonoscopy, and FOBT), in which month they had undergone the respective CS examination, and what kind of physician had carried out the CS examination.

\section{Results}

\section{Attendance of a Cancer Screening Examination Since T1}

Altogether, 205 men (20\%) of men who were followed up in Study 2 underwent a CS examination. Of the IAs $(n=261), 85$ $(32.6 \%)$ stated that they had attended a CS examination since T1, in the group of the former NAs $(n=771)$, the ratio was smaller, as expected: $120(15.6 \%)$. The difference in attendance rate was significant, $\chi^{2}(1, N=1,032)=35.4, p<.001$. The majority of men $(73 \%)$ reported having undergone the standard CS examination for men (prostate CS with DRE, $n=150), 128$ men $(62 \%)$ reported a colorectal CS with FOBT, 113 men (55\%) had a PSA test, and 50 underwent a colonoscopy.

\section{Predictors of Cancer Screening Participation in Former Non-Attenders and Irregular Attenders}

Binary logistic regression analyses were used to predict CS participation 12 months after completing the T1 questionnaire. We 
conducted separate analyses for NAs and IAs, the binary criterion was attendance at a prostate and/or colorectal CS examination (Yes vs. No) since T1. Results are displayed in Table 4.

For (former) NAs, intention and subjective norm were significantly associated with CS participation. Higher intention led to significantly increased odds to have attended a CS for the first time. Furthermore, increments in subjective norm of one unit (1-7, interval .33) at T1 significantly increased the odds of having attended by 1.2. No other significant association was found between CS participation and the predictors. For IAs, subjective norm and intention at T1 were significantly associated with CS participation after controlling for all other variables. As for (former) NAs, higher intention led to significantly increased odds of having attended a CS. With regard to subjective norm, the direction of the association was, however, opposite to that of NAs. Increments of one unit (1-7, interval .33) in subjective norm assessed at T1 decreased the odds of having attended by 0.80 . In order to illuminate the differential effects of subjective norm on CS behavior of former NAs and IAs, we compared men from the lowest quartile with men from the highest quartile of subjective norm. For former NAs, those men who had reported a high subjective norm at $\mathrm{T} 1$ were more likely to have attended a standard CS examination since T1 (21.2\%), in comparison to men who had experienced low subjective norm $(9.5 \%)$, whereas the opposite pattern was observed for IAs. Reports of low subjective norm were associated with a higher attendance rate $(35.7 \%)$, in comparison to reports of high subjective norm $(27.7 \%)$.

In order to rule out the possibility that this unexpected finding was overly influenced by collinearity between subjective norm and other variables (descriptive norm most notably), we computed the intercorrelations among all predictors for Study 2 participants only (results not shown). The correlation between subjective and descriptive norm while being significant was not excessively large $\left(r_{\text {Non-Attenders }}=.23, r_{\text {Irregular Attenders }}=.20\right)$. The correlations of

Table 4

Logistic Regression of Cancer Screening Uptake in Former Non-Attenders (NAs) and Irregular Attenders (IAs) on Sociodemographic and Psychological Variables (Study 2)

\begin{tabular}{|c|c|c|c|c|}
\hline \multirow[b]{2}{*}{ Predictor } & \multicolumn{2}{|c|}{ NAs $(n=771)$} & \multicolumn{2}{|c|}{ IAs $(n=261)$} \\
\hline & OR & $95 \% \mathrm{CI}$ & OR & $95 \% \mathrm{CI}$ \\
\hline \multicolumn{5}{|l|}{ Sociodemographic } \\
\hline $\operatorname{Age}^{\mathrm{a}}$ & 1.00 & $0.95-1.04$ & 1.02 & $0.96-1.09$ \\
\hline Partner status ${ }^{\mathrm{b}}$ & 1.72 & $0.55-5.41$ & 2.04 & $0.64-6.54$ \\
\hline Household size $^{a}$ & 1.01 & $0.84-1.22$ & 0.85 & $0.64-1.13$ \\
\hline Family income $^{\mathrm{a}}$ & 1.01 & $0.96-1.07$ & 1.03 & $0.96-1.11$ \\
\hline \multicolumn{5}{|l|}{ Psychological } \\
\hline Intention $^{\mathrm{a}}$ & 1.18 & $1.01-1.37$ & 1.29 & $1.03-1.61$ \\
\hline Attitude ${ }^{\mathrm{a}}$ & 0.95 & $0.74-1.22$ & 1.07 & $0.74-1.53$ \\
\hline Subjective norm ${ }^{\mathrm{a}}$ & 1.20 & $1.05-1.39$ & 0.80 & $0.66-0.97$ \\
\hline $\mathrm{PBC}^{\mathrm{a}}$ & 1.16 & $0.96-1.41$ & 1.15 & $0.89-1.49$ \\
\hline Descriptive norm ${ }^{\mathrm{a}}$ & 1.00 & $0.99-1.01$ & 1.01 & $0.99-1.02$ \\
\hline
\end{tabular}

Note. $\quad N=1,032 . \mathrm{NAs}=($ former $)$ non-attenders; IAs $=($ former $)$ irregular attenders; $\mathrm{OR}=$ odds ratio; $\mathrm{CI}=$ confidence interval. Significant odds ratios are shown in bold.

${ }^{\mathrm{a}}$ Continous variable. ${ }^{\mathrm{b}}$ Dichotomous variable $(0$ [reference category] $=$ no partner, 1 = with partner). Nagelkerke's $R^{2}$ for non-attenders $=.07$, for irregular attenders $=.11$.
SN with PBC and attitude were even lower (around $r=.08$ ). Entering only one norm construct without the other did not substantially change the model (likewise when removing the other TPB constructs, apart from intention). Thus, multicollinearity between subjective norm and other variables under study does not appear to be the reason for the unexpected finding regarding subjective norm.

\section{Discussion}

The main goal of our research was to examine psychological variables in the context of men's CS intention and behavior. We used an extended model of the theory of planned behavior, adding descriptive norm. When comparing NAs, IAs, and RAs in Study 1, we found small differences in sociodemographic variables between the groups; the greatest difference was found in age, with RAs being on average about 4 years older than NAs. Substantial differences among the three groups were, however, observed on all psychological variables. Linear increments from NAs to IAs to RAs on all extended TPB variables were apparent. Using multivariate hierarchical regression analysis it became even more evident that sociodemographic variables can explain only minimal variance in CS intention. TPB variables on the other hand sharply increased the explained variance in CS intention. The finding that attitude and $\mathrm{PBC}$ are predictive of CS intention is in line with the few studies on CS intention conducted with men (Berglund et al., 2005; Hahm et al., 2007). Study 1 also identified subjective norm as an important predictor of CS intention, while descriptive norm was able to further increase the variance explained over and above classical TPB variables, thus supporting our hypothesis. The intention of men to undergo a CS examination was not only influenced by what they think significant others expect them to do, but also by their perception of how other comparable men behave regarding CS. Our study thus shows that findings such as these-that descriptive norm is important in the process of health-relevant intention-formation (Rivis \& Sheeran, 2003)can be applied to the so far understudied area of CS in men. The significant interaction between subjective and descriptive norm suggests that descriptive norm becomes even more important when subjective norm is low, for example because there is no partner/family exerting their influence toward attending a CS examination or because the partner/family/friends are themselves ambivalent or have a negative attitude toward CS, respectively. In these scenarios men may be guided even more by what other men their age do.

The results of the longitudinal study (Study 2), which followed up (former) nonattenders (NAs) and irregular attenders (IAs) who at T1 stated that they were either thinking about screening or intended to screen, support the utility of behavioral intention as an important determinant of behavior. In both groups of men, (former) NAs and IAs, the intention to undergo a CS examination within the next 12 months significantly predicted actual uptake of such an examination, which was assessed 12 months later at T2. Logistic regression also revealed subjective norm to be a predictor of CS attendance, emphasizing again the importance of social norms, but, interestingly and unexpectedly, the directions of association in the two subgroups of men were disparate. For former NAs, a high 
subjective norm (assessed at T1) resulted in a higher, whereas for IAs, in a lower likelihood to have undergone a CS examination. Though speculative and uncorroborated, the construct of psychological reactance may offer one possible explanation for the latter finding. In four focus group discussions conducted by a male interviewer prior to the present research (Sieverding \& Dauven, 2005), participants were-among other questionsasked: "What would you do if your partner made an appointment for a cancer screening for you?" An excerpt from the transcript exemplifies the reluctance and negative reactions toward attempts at being influenced by significant others such as the partner: P.3: "Then she should go!" Interviewer: "But she signed you up!" P.4: "I do those things alone. I make my appointments myself." Interviewer: "So you would not go there?" P.4: "I'd say-you go there - I did not make that appointment-hey, where do I live?" P.5: "My former wife always bugged me - Go there and do this and that. I exchanged the wife and am not sick anymore. I'm doing just fine ...."

Psychological reactance effects in health-relevant behavior have been observed in different domains (Matire, Stephens, Druley, \& Wojno, 2002; Miller, Burgoon, Grandpre, \& Alvaro, 2006). Orbell and Hagger (2006) studied women's clinic attendance for treatment and follow-up after having received an abnormal cervical CS result. In addition to traditional TPB variables, a measure of psychological reactance was administered, which enhanced the prediction of behavior. Although we did not include an explicit measure of psychological reactance, the fact that NAs reacted positively to a high subjective norm, whereas IAs reacted negatively, is striking. The latter group may have felt more restricted in their freedom because they already knew they were able to perform the behavior. In many studies on TPB and health-relevant behavior, subjective norm emerged as the weakest predictor. Our interpretation that some subgroups of people might react with reactance to perceived social pressure, may explain this finding and hopefully inspire future research.

PBC did not emerge as a significant predictor of behavior. Cooke and French (2008) found in their meta-analysis that PBC was a relatively unimportant predictor of screening behavior, and argued that screening attendance may be an example of a behavior where perceptions of control do not reflect actual control. We think that the operationalization of PBC may also be a reason for this finding in our study. Uptake of a CS examination in a noninvitation system includes different actions for preparation: One has to remember that one wanted to undergo a CS examination in a certain time frame, one has to make an appointment with a physician, one has to remember this appointment, and one has to attend the appointment. In our study, PBC regarding CS attendance was assessed in a rather general way and in a manner that did not address these different steps of action; perhaps the prediction of PBC on uptake of CS examinations would be improved if the different steps in the appointment process were reflected in the operationalization of PBC.

A limitation of the present research is the assessment of the behavior by self-report. When comparing self-report with medical record audit for several cancer tests Hall et al. (2004) demonstrated overreporting of previous cancer test participation by self-report. We made strong efforts, however, to limit the overreporting bias by asking participants in Study 2 in detail what kind of CS examination(s) they had undergone, in which month, and conducted by which physician. A further limitation is the fact that we used a single outcome variable for CS attendance (prostate and colorectal CS examinations combined). We chose this measure mainly because in Germany the two examinations are very often combined. Another reason was that the sample sizes would have been too small to conduct separate analyses for prostate and colorectal CS. Nevertheless, we are aware of the fact that the examinations that are offered for prostate and colorectal CS (especially DRE and FOBT) include very different experiences. The digital rectal examination of the prostate, in particular, is by many men experienced as very unpleasant and embarrassing. These perceptions constitute important barriers for CS attendance (Nagler et al., 2005) as has been revealed in focus group discussions with U.S. men (Dale, Sartor, Davis, \& Bennett, 1999) as well as with German men (Sieverding \& Dauven, 2005). Consequently, psychological predictors of prostate and colorectal CS should be differentiated in future studies.

The variance in CS uptake accounted for by the variables under study was quite small: Nagelkerke's $R^{2}$ for NA $=.07$, for IA $=$ .11. The prediction of (general) screening uptake from TPB constructs appears poorer compared to other health behaviors (Conner \& Sparks, 2005; Cooke \& French, 2008). A possible explanation for this may be the long time frame (in our Study 12 months); for another health-related behavior (condom use) it was shown that the intention-behavior gap widens the longer the time interval between assessment of intention and behavior becomes (Sheeran \& Orbell, 1998). Also, lack of experience with a behavior (in this case cancer screening) may be associated with a less stable intention to perform that behavior (Sheeran, Conner, \& Norman, 2001). The results from our study lend support to this proposal since the variance in CS behavior accounted for was smaller for first time attenders than for those who attended for a repeated time.

In sum, our study is the first large longitudinal study on men's CS behavior that analyzed psychological as well as sociodemographic variables. Our research demonstrated the utility of the theory of planned behavior to explain men's cancer screening intention and behavior. We addressed the need for expansion of the normative component that was proposed by several researchers (Armitage \& Conner, 2001; Rivis \& Sheeran, 2003) and were able to show that social influences play an important role in the context of men's CS intention when assessed not only by subjective norm, but by descriptive norm, and when assessment occurs using reliable multiple items. This knowledge offers the possibility of planning psychoeducational interventions to improve men's attendance rates in CS. Our research indicates that interventions should not only address attitude (Wardle et al., 2003) and PBC toward CS, but that the subjective and the descriptive norms have to be taken into account as well. Our study also supported the previous finding that predictors of screening attendance may differ as a function of past behavior (Norman \& Conner, 1996), suggesting that interventions should be tailored to the different needs and motivational states of men who do or do not at all have CS experience. The findings of our study might have implications for other areas of men's preventive health behavior.

\section{References}

Ajzen, I. (1991). The theory of planned behavior. Organizational Behavior and Human Decision Processes, 50, 179-211.

Ajzen, I. (2002a). Constructing a TpB-questionnaire: Conceptual and 
methodological considerations [Electronic Version]. Retrieved February 28, 2008 from http://people.umass.edu/aizen/pdf/tpb.measurement.pdf

Ajzen, I. (2002b). Residual effects of past on later behavior: Habituation and reasoned action perspectives. Personality and Social Psychology Review, 6, 107-122.

Armitage, C. J., \& Conner, M. (2001). Efficacy of the theory of planned behaviour: A meta-analytic review. British Journal of Social Psychology, 40, 471-499.

Berglund, G., Nilsson, S., \& Nordin, K. (2005). Intention to test for prostate cancer. European Journal of Cancer, 41, 990-997.

Breen, N., Wagener, D. K., Brown, M. L., Davis, W. W., \& BallardBarbash, R. (2001). Progress in cancer screening over a decade: Results of cancer screening from the 1987, 1992, and 1998 National Health Interview Surveys. Journal of the National Cancer Institute, 93, 17041713.

Cialdini, R. B., Reno, R. R., \& Kallgren, C. A. (1990). A focus theory of normative conduct: Recycling the concept of norms to reduce littering in public places. Journal of Personality and Social Psychology, 58, 10151026.

Classen, M., \& Lambert, R. (2008). Colorectal cancer screening in EuropeA survey of the international digestive cancer alliance between November 2004 and March 2007. Zeitschrift fuer Gastroenterologie, 46, S23-S24.

Cokkinides, V. E., Chao, A., Smith, R. A., Vernon, S. W., \& Thun, M. J. (2003). Correlates of underutilization of colorectal cancer screening among U.S. adults, age 50 years and older. Preventive Medicine, 36, $85-91$.

Conner, M., \& Sparks, P. (2005). Theory of planned behaviour and health behaviours. In M. Conner \& P. Norman (Eds.), Predicting health behaviour: Research and practice with social cognition models. 2nd ed. (pp. 171-222). Buckingham, England: Open University Press.

Cooke, R., \& French, D. P. (2008). How well do the theory of reasoned action and theory of planned behaviour predict intentions and attendance at screening programmes? A meta-analysis. Psychology \& Health, 23, $745-765$.

Dale, W., Sartor, O., Davis, T., \& Bennett, C. L. (1999). Understanding barriers to the early detection of prostate cancer among men of lower socioeconomic status. The Prostate Journal, 1, 174-184.

Deutsch, M., \& Gerard, H. B. (1955). A study of normative and informational social influences upon individual judgment. Journal of Abnormal \& Social Psychology, 51, 629-636.

DeVellis, B. M., Blalock, S. J., \& Sandler, R. S. (1990). Predicting participation in cancer screening: The role of perceived behavioral control. Journal of Applied Social Psychology, 20, 639-660.

Evans, R. E. C., Brotherstone, H., Miles, A., \& Wardle, J. (2005). Gender differences in early detection of cancer. Journal of Men's Health \& Gender, 2, 209-217.

Faivre, J., Dancourt, V., Lejeune, C., Tazi, M. A., Lamour, J., Gerard, D., et al. (2004). Reduction in colorectal cancer mortality by fecal occult blood screening in a French controlled study. Gastroenterology, 126, $1674-1680$.

Francis, J., Eccles, M., Johnson, M., Walker, A., Grimshaw, J., Foy, R., et al. (2004). Constructing questionnaires based on the theory of planned behaviour. A manual for health services researchers [Electronic Version] from http://www.rebeqi.org/ViewFile.aspx?itemID $=212$

Godin, G., \& Kok, G. (1996). The theory of planned behavior: A review of its applications to health-related behaviors. American Journal of Health Promotion, 11, 87-98.

Hahm, M.-I., Choi, K. S., Kye, S.-Y., Kwak, M.-S., \& Park, E.-C. (2007). Factors influencing the intention to have stomach cancer screening. Journal of Preventive Medicine \& Public Health/Yebang Uihakhoe Chi, 40, 205-212.

Hall, H. I., Van Den Eeden, S. K., Tolsma, D. D., Rardin, K., Thompson, T., Hughes Sinclair, A., et al. (2004). Testing for prostate and colorectal cancer: Comparison of self-report and medical record audit. Preventive Medicine, 39, 27-35.

Hardcastle, J. D., Chamberlain, J. O., Robinson, M. H., Moss, S. M., Amar, S. S., Balfour, T. W., et al. (1996). Randomised controlled trial of faecal-occult-blood screening for colorectal cancer. Lancet, 348, 14721477.

Kallgren, C. A., Reno, R. R., \& Cialdini, R. B. (2000). A focus theory of normative conduct: When norms do and do not affect behavior. Personality and Social Psychology Bulletin, 26, 1002-1012.

Klug, S. J., Hetzer, M., \& Blettner, M. (2005). Screening for breast and cervical cancer in a large German city: Participation, motivation and knowledge of risk factors. European Journal of Public Health, 15, $70-77$.

Malila, N., Oivanen, T., \& Hakama, M. (2008). Implementation of colorectal cancer screening in Finland: Experience from the first three years of a public health programme. Zeitschrift fuer Gastroenterologie, 46, S25-S28.

Marteau, T. M., Johnston, M., Kidd, J., \& Michie, S. (1992). Psychological models in predicting uptake of prenatal screening. Psychology \& Health, 6, 13-22.

Matire, L. M., Stephens, M. A. P., Druley, J. A., \& Wojno, W. C. (2002). Negative reactions to received spousal care: Predictors and consequences of miscarried support. Health Psychology, 21, 167-176.

Miller, C. H., Burgoon, M., Grandpre, J. R., \& Alvaro, E. M. (2006). Identifying principal risk factors for the initiation of adolescent smoking behaviors: The significance of psychological reactance. Health Сотmunication, 19, 241-252.

Nagler, H. M., Gerber, E. W., Homel, P., Wagner, J. R., Norton, J., Lebovitch, S., et al. (2005). Digital rectal examination is barrier to population-based prostate cancer screening. Urology, 65, 1137-1140.

Nijs, H. G., Essink-Bot, M. L., DeKoning, H. J., Kirkels, W. J., \& Schroder, F. H. (2000). Why do men refuse or attend population-based screening for prostate cancer? Journal of Public Health Medicine, 22, 312-316.

Norman, P., \& Conner, M. (1996). Predicting health-check attendance among prior attenders and nonattenders: The role of prior behavior in the theory of planned behavior. Journal of Applied Social Psychology, 26, $1010-1026$

Orbell, S., \& Hagger, M. (2006). 'When no means no': Can reactance augment the theory of planned behavior? Health Psychology, 25, 586-594.

Reno, R. R., Cialdini, R. B., \& Kallgren, C. A. (1993). The transsituational influence of social norms. Journal of Personality and Social Psychology, 64, 104-112.

Rivis, A., \& Sheeran, P. (2003). Descriptive norms as an additional predictor in the theory of planned behaviour: A meta-analysis. Current Psychology: Developmental, Learning, Personality, Social, 22, 218-233.

Robert Koch-Institut, \& Gesellschaft der epidemiologischen Krebsregister (Eds.). (2008). Krebs in Deutschland 2003-2004 [Cancer in Germany 2003-2004] (6th Ed.). Berlin.

Seeff, L. C., Nadel, M. R., Klabunde, C. N., Thompson, T., Shapiro, J. A., Vernon, S. W., et al. (2004). Patterns and predictors of colorectal cancer test use in the adult U.S. population. Cancer, 100, 2093-2103.

Sheeran, P., Conner, M., \& Norman, P. (2001). Can the theory of planned behavior explain patterns of health behavior change? Health Psychology, $20,12-19$.

Sheeran, P., \& Orbell, S. (1998). Do intentions predict condom use? Meta-analysis and examination of six moderator variables. British Journal of Social Psychology, 37, 231-250.

Sieverding, M., \& Dauven, S. (2005, September). Psychological Barriers to Cancer Screening in German Men: Focus Group Findings. Paper presented at the 19th Annual Conference of the European Health Psychology Society.

Sieverding, M., Matterne, U., \& Ciccarello, L. (2008). Gender differences 
in FOBT use: Evidence from a large German sample. Zeitschrift fuer Gastroenterologie, 46, 47-51.

Sieverding, M., Matterne, U., Ciccarello, L., \& Luboldt, H.-J. (2008). Prostatakarzinom-Früherkennung in Deutschland - Untersuchung einer repräsentativen Bevölkerungsstichprobe. [Early detection of prostate cancer in Germany - a survey with a representative sample]. Der Urologe, 47, 1233-1238.

Swan, J., Breen, N., Coates, R. J., Rimer, B. K., \& Lee, N. C. (2003).
Progress in cancer screening practices in the United States: Results from the 2000 National Health Interview Survey. Cancer, 97, 15281540 .

Wardle, J., Williamson, S., McCaffery, K., Sutton, S., Taylor, T., Edwards, R., et al. (2003). Increasing attendance at colorectal cancer screening: Testing the efficacy of a mailed, psychoeducational intervention in a community sample of older adults. Health Psychology, $22,99-105$.

\title{
New Editor Appointed for Health Psychology, 2011-2016
}

Division 38 (Health Psychology) of the American Psychological Association is pleased to announce the appointment of a new editor for Health Psychology for a 6-year term beginning in 2011. As of July 1, 2010, all new manuscripts should be directed to:

\author{
Anne E. Kazak, PhD \\ The Children's Hospital of Philadelphia and \\ University of Pennsylvania \\ 34th and Civic Center Blvd. \\ Room 1486 CHOP North \\ Philadelphia, PA 19104-4399
}

Electronic manuscript submission: As of July 1, 2010, manuscripts should be submitted electronically to the new editor via the journal's Manuscript Submission Portal: http://www.apa.org/ journals/hea/submission.html

Manuscript submission patterns make the precise date of completion of the 2010 volumes uncertain. The current editor, Robert M. Kaplan, $\mathrm{PhD}$ will receive and consider new manuscripts through June 30, 2010. Should 2010 volumes be completed before that date, manuscripts will be redirected to the new editor for consideration in the 2011 volume. 